\title{
Editorial: Unnatural Behaviour
}

Once again great play is being made of the possibility that chimpanzees are capable of learning human language. A pparently, if supplied with a specially designed computer keyboard similar to that supplied to severely retarded human infants, Panbanisha and $\mathrm{K}$ anzi, two bonobo pigmy chimpanzees are able to communicate with their trainers. According to Professor Sue Savage-R umbaugh, the chief experimenter, the chimps are now beginning to produce real sentences. T his is being taken to show that they have a sense of self and of tense.

With animal welfare currently a hotly contested political issue, and talk of apes in Australia being accorded legal rights, much may hang on all of this. If apes can talk, yet another boundary between humans and beasts is crossed, even more if animals are self-conscious. Whether the experiments show any of this must remain in some doubt. I t looks as if some sort of T uring test is being played on the unfortunate creatures. We do not yet know if it shows more than that they are rather clever at doing what their reinforcers want, without necessarily understanding whatever thoughts it is they are being credited with. And maybe it is just this that we will never know.

These are clearly deep questions, with all the delightful inconclusiveness which arises whenever the evidence underdetermines the conclusions we ought to draw. But one vital question has not, to our knowledge, so far been raised. Can it be right to give chimps a taste for playing with computers? I sn't it unnatural for them to spend their days chained to their word-processor, just like some unfortunate academic? I s there a danger of breeding a race of simian computer nerds? Chomsky is reputed to have said that attempting to teach linguistic skills to animals is like trying to teach humans to flap their arms and fly. But rather more worrying would be the unnaturalness of chimps unable to function without keyboard and terminal. 